\title{
OPTIMIZATION OF MALACHITE GREEN DYE REMOVAL BY SEPIOLITE CLAY USING A CENTRAL COMPOSITE DESIGN
}

\author{
CORUH S. ${ }^{1, *}$ \\ ELEVLI $S^{2}$
}

\author{
${ }^{1}$ Department of Environmental Engineering \\ Ondokuz Mayis University, 55139 Samsun, Turkey \\ ${ }^{b}$ Department of Industrial Engineering \\ Ondokuz Mayıs University, 55139 Samsun, Turkey
}

*to whom all correspondence should be addressed:

\begin{abstract}
In this study, a four-factor five-level Central Composite Design (CCD) was applied to develop mathematical model and optimize process parameters for malachite green dye (MG) removal from aqueous solutions using sepiolite. The individual, combined, and quadratic effects of four experimental factors (initial pH of solution, contact time, initial dye concentration, and sepiolite dosage) on dye adsorption were studied. Based on the analysis of variance (ANOVA) results, the order of factors from high to low contribution on removal efficiency was found as initial dye concentration, sepiolite dosage, initial dye concentration*initial dye concentration, sepiolite dosage*sepiolite dosage, and contact time with respect to sum of squares. Optimization results showed that the optimal settings for significant experimental factors were initial dye concentration $=77 \mathrm{mg} \mathrm{l}^{-1}$, sepiolite dosage $=26 \mathrm{~g} \mathrm{I}^{-1}$, and contact time $=42 \mathrm{~min}$. At this setting, predicted maximum removal efficiency was over $99 \%$.
\end{abstract}

Keywords: Adsorption, Central Composite Design, Malachite Green Dye, Optimization, Sepiolite

\section{Introduction}

Pigment and dyes are widely used in textiles, paper, leather, plastics, rubber, carpet, pharmaceutical, and cosmetic industries (Özdemir et al., 2007; Tor and Cengeloglu, 2006). About 10,000 different dyes weighing approximately 0.7 million tons are produced annually for various industrial processes. A considerable percentage of these dyes are released into the effluent during the dyeing process. Direct discharge of these effluents into municipal wastewater plants and/or environment may cause the formation of toxic carcinogenic breakdown products. Over $90 \%$ of some 4000 dyes tested in an ETDA (Ecological and Toxicological Association of the dyestuff) survey had lethal dose $50 \%\left(\mathrm{LD}_{50}\right)$ values greater than $200 \mathrm{mg} \mathrm{kg}^{-1}$. The highest rates of toxicity were found amongst basic and diazo direct dyes (Garg et al., 2004; Hameed et al., 2008; Nethaji et al., 2010; Mona et al., 2011). Malachite green (MG), also called aniline green and basic green 4 , is a toxic chemical primarily used as a dye. Though the external use of MG as an antiseptic, antibacterial and antiprotozoan agent is well known but its oral consumption is toxic, hazardous and carcinogenic due to presence of nitrogen. Contact to malachite green with skin and eye causes irritation with redness and pain. The available toxicological information reveals that in the tissues of fish and mice MG easily reduces to persistable leuco-Malachite Green, which acts as a tumor promotor. MG has a complicated chemical structure; it is resilient to fading on exposure to light and water and is, therefore, the removal of MG from wastewater before discharging to the environment is necessary and very important (Önal et al., 2006; Baek et al., 2010; Ahmad and Alrozi, 2011). 
In order to remove dyes from aqueous solutions, many chemical or biological treatments such as adsorption, coagulation, fenton process, ozonation, electrochemical oxidation, ultrasonic irradiation, and membrane process have been used either individually or together. Adsorption techniques to remove dyes from water have been widely used. It has been found to be an economical and effective treatment method for removal of dyes due to its sludge free clean operation. Adsorption processes using activated carbons have been widely proposed and used for the removal of both organic and inorganic pollutants from aqueous effluents. However, commercially available activated carbons are expensive, and in recent years, a great deal of effort has been put into the proposal and usage of lowcost adsorbents prepared from naturally occurring materials and wastes for the removal of dyes from wastewaters (Ay et al., 2009; Uğurlu, 2009; Im et al., 2012; Somayajula et al., 2012;). In the recent years, for the removal of different type of substances from wastewaters, several materials have been evaluated as adsorbent like silicagel, clay, perlite, zeolite, sepiolite, hydroxyapatite, fly ash, unburned carbon, coir pith carbon, pulp fiber, shale oil ash, silkworm pupa, and others (Lazarevic et al., 2007; Şener, 2008; Alpat et al., 2008; Neta et al., 2011; Singh et al., 2011).

The clay mineral sepiolite is currently used as raw material due to its powerful sorbent properties (Rytwo et al., 1998). Sepiolite has an open structure exhibiting a microfibrous morphology with a high specific surface area (around $340 \mathrm{~m}^{2} \mathrm{~g}^{-1}$ ) and a large micropore volume (around $0.44 \mathrm{~cm}^{3} \mathrm{~g}^{-1}$ ). The sorptive property of sepiolite particularly renders it invaluable as a bleaching, and clarifying agent, filter aid, industrial adsorbent, and a spectrum of uses ranging from cosmetics to paints and even fertilizers. Most of the studies were about the sorption of heavy metal ions, organic molecules and ions, ammonium and phosphate, color, and other undesirable components, dyes, phenol, and lignin (Balci, 2004, Garg et al., 2004; Turan et al., 2005; Zhao et al., 2008; Bingol et al., 2010).

Response Surface Methodology (RSM) is an experimental technique invented to find the optimal response within the specified ranges of the factors. Since "optimal" often implies a minimum or maximum, optimization designs involve at least three levels of each factor so that curvature may be estimated. Central Composite Design (CCD) is one of the most commonly used RSM designs (Im et al, 2012; Amani-Ghadima et al., 2013). CCD is often used in chemical processes when the design plan calls for sequential experimentation because these designs can incorporate information from a properly planned factorial experiment. In this study, four-factor five-level CCD was used to determine the effects of initial $\mathrm{pH}$ of solution, contact time, initial dye concentration and sepiolite dosage on the adsorption process and to find optimum settings.

\section{Materials and methods}

\subsection{Materials}

Sepiolite sample used in the experiments was received from Aktaş Lületaşı Co. in Eskişehir, Turkey. Sepiolite was washed thoroughly with double distilled water to remove the dirt and other foreign matter and dried at $70{ }^{\circ} \mathrm{C}$ for a period of $3-5 \mathrm{~h}$.

Table 1. Some properties of malachite green dye

\begin{tabular}{cc}
\hline Basic Dyes Properties & Malachite green \\
\hline C.I. No & 42000 \\
\hline CAS No & $5596-64-2$ \\
\hline Molecular Formula & $\mathrm{C}_{23} \mathrm{H}_{25} \mathrm{ClN}_{2}$ \\
\hline Molecular Weight $\left(\mathrm{g} \mathrm{mol}^{-1}\right)$ & 364.92 \\
\hline Melting Point & $164{ }^{\circ} \mathrm{C}$ \\
\hline C.I. Name & Basic Dye \\
\hline Molecular Structure & \\
\hline
\end{tabular}




\subsection{Methods}

The basic dye, malachite green $\left(\mathrm{C}_{23} \mathrm{H}_{25} \mathrm{CIN}_{2}\right)$, was selected for adsorption studies.

The stock solution of $1000 \mathrm{mg} \mathrm{l}^{-1}$ was prepared by dissolving accurately weighed amounts of malachite green in $1000 \mathrm{~mL}$ distilled water. The stock solution was further diluted to obtain desired concentration ranging from 10 to $250 \mathrm{mg} \mathrm{l}^{-1}$. Table 1 shows some properties of malachite green dye. The $\mathrm{pH}$ of the solutions was adjusted with $\mathrm{HNO}_{3}$ and $\mathrm{NaOH}$ solutions by using a WTW $330 \mathrm{pH}$-meter with a combined $\mathrm{pH}$ electrode.

\subsection{Adsorption procedure}

Batch experiments based on CCD were conducted at random to study the effect of the pre-selected four operating variables on the dye removal efficiecy of the sepiolite. For adsorption of the dye on sepiolite, different weighted amounts of the sepiolite $\left(0.5-40 \mathrm{~g} \mathrm{l}^{-1}\right)$ were equilibrated with $100 \mathrm{ml}$ of solution initially containing $10-250 \mathrm{mg}^{-1}$ of the malachite green dye. The $\mathrm{pH}$ of the dye solutions was adjusted (2.0-9.0) with $\mathrm{HCl}$ or $\mathrm{NaOH}$ solutions by using WTW $330 \mathrm{pH}$-meter with a combined pH electrode. The adsorption experiments were conducted in a bath shaker for $23^{\circ} \mathrm{C}$ at $175 \mathrm{rpm}$ at different contact times (5-91 min.). The equilibrated samples were taken out, and the aqueous solution phase was separated from the adsorbent using a centrifuge to make it adsorbent free. The dye concentration in supernetant solution was determined using the UV-visible spectrophotometer at $617 \mathrm{~nm}$. All experiments were conducted in duplicate and the average values were used for data analysis.

The removal efficiency $(E)$ of the sepiolite on malachite green dye was calculated according to the following formula:

$E(\%)=\frac{C_{0}-C}{C_{0}} \times 100$

where $C_{o}$ is the initial concentration of the dye solution, and $C$ is the final concentration of the dye solution.

\subsection{Central Composite Design}

Response Surface Methods use specific experimental design combinations to develop mathematical models with linear, quadratic, and interaction terms to find optimum performance from a given set of factors and response variables (DeCarlo, 2007). The two most frequently designs used in response surface modeling are Central Composite Design (CCD) and Box-Behnken Design (BBD). These designs are capable of fitting a second order prediction equation $\left(\hat{y}=\hat{\beta}_{0}+\sum_{i=1}^{k} \hat{\beta}_{i} x_{i}+\sum_{i=1}^{k} \hat{\beta}_{i i} x_{i}^{2}+\sum \sum_{i<j} \hat{\beta}_{i j} x_{i} x_{j}\right)$ for the response.

CCD consists of cube points for the estimation of linear and interaction effects, center points to check for curvature, and axial points to estimate quadratic terms. Alpha $(\alpha)$ for axial points is the distance of each axial point from the center. A central composite design with five center points and $\alpha=2$ was used to conduct the experiments (Table 2). After performing the experiments according to the design, removal efficiencies were recorded as response variable. The experimental parameters were analyzed and optimized in the MINITAB 16 statistical software environment.

Table 2. Experimental data set and design matrix

\begin{tabular}{lcccccc}
\hline \multirow{2}{*}{ Factors } & \multirow{2}{*}{ Symbols } & \multicolumn{5}{c}{ Levels of Factors } \\
\cline { 3 - 7 } & $X_{1}$ & $\mathbf{- \alpha}(\mathbf{- 2 . 0 0 0 )}$ & $\mathbf{- 1}$ & $\mathbf{0}$ & $\mathbf{+ 1}$ & $\mathbf{+ \alpha}(\mathbf{+ 2 . 0 0 0 )}$ \\
\hline Initial pH & $X_{2}$ & 0.5 & 10.375 & 20.250 & 30.125 & 40 \\
\hline Sepiolite Dosage $\left(\mathrm{g} \mathrm{I}^{-1}\right)$ & $X_{3}$ & 10 & 70 & 130 & 190 & 250 \\
\hline Initial Dye Conc. $\left(\mathrm{mg} \mathrm{I}^{-1}\right)$ & $X_{4}$ & 5 & 33.75 & 62.50 & 91.25 & 120 \\
\hline Contact Time (min) & & & & & & \\
\hline
\end{tabular}




\begin{tabular}{|c|c|c|c|c|c|}
\hline Run & $x_{1}$ & $x_{2}$ & $x_{3}$ & $x_{4}$ & Efficiency (\%) \\
\hline 1 & 3.75 & 10.375 & 70 & 33.75 & 90.85 \\
\hline 2 & 7.25 & 10.375 & 70 & 33.75 & 93.10 \\
\hline 3 & 3.75 & 30.125 & 70 & 33.75 & 98.95 \\
\hline 4 & 7.25 & 30.125 & 70 & 33.75 & 98.71 \\
\hline 5 & 3.75 & 10.375 & 190 & 33.75 & 89.85 \\
\hline 6 & 7.25 & 10.375 & 190 & 33.75 & 90.21 \\
\hline 7 & 3.75 & 30.125 & 190 & 33.75 & 92.60 \\
\hline 8 & 7.25 & 30.125 & 190 & 33.75 & 92.10 \\
\hline 9 & 3.75 & 10.375 & 70 & 91.25 & 97.48 \\
\hline 10 & 7.25 & 10.375 & 70 & 91.25 & 97.56 \\
\hline 11 & 3.75 & 30.125 & 70 & 91.25 & 99.57 \\
\hline 12 & 7.25 & 30.125 & 70 & 91.25 & 99.82 \\
\hline 13 & 3.75 & 10.375 & 190 & 91.25 & 85.47 \\
\hline 14 & 7.25 & 10.375 & 190 & 91.25 & 88.45 \\
\hline 15 & 3.75 & 30.125 & 190 & 91.25 & 89.88 \\
\hline 16 & 7.25 & 30.125 & 190 & 91.25 & 90.20 \\
\hline 17 & 2.00 & 20.250 & 130 & 62.50 & 98.17 \\
\hline 18 & 9.00 & 20.250 & 130 & 62.50 & 99.42 \\
\hline 19 & 5.50 & 0.500 & 130 & 62.50 & 75.60 \\
\hline 20 & 5.50 & 40.000 & 130 & 62.50 & 99.69 \\
\hline 21 & 5.50 & 20.250 & 10 & 62.50 & 98.80 \\
\hline 22 & 5.50 & 20.250 & 250 & 62.50 & 76.40 \\
\hline 23 & 5.50 & 20.250 & 130 & 5.00 & 86.12 \\
\hline 24 & 5.50 & 20.250 & 130 & 120.00 & 98.72 \\
\hline 25 & 5.50 & 20.250 & 130 & 62.50 & 98.63 \\
\hline 26 & 5.50 & 20.250 & 130 & 62.50 & 98.65 \\
\hline 27 & 5.50 & 20.250 & 130 & 62.50 & 98.92 \\
\hline 28 & 5.50 & 20.250 & 130 & 62.50 & 98.77 \\
\hline 29 & 5.50 & 20.250 & 130 & 62.50 & 98.83 \\
\hline 30 & 5.50 & 20.250 & 130 & 62.50 & 98.60 \\
\hline 31 & 5.50 & 20.250 & 130 & 62.50 & 98.88 \\
\hline
\end{tabular}

\section{Results and discussion}

\subsection{Characterization of the sepiolite}

The chemical composition of the sepiolite slag was evaluated by using X-ray Fluorescence techniques (Rigaku ZSX Primus). The chemical composition of the sepiolite is given in Table 3. The BET specific surface area was measured to be $82.35 \mathrm{~m}^{2} \mathrm{~g}^{-1}$ from $\mathrm{N}_{2}$ adsorption isotherms with a sorptiometer (Quantachrome Co., NOVA 2200). In this study, scanning electron microscopy (SEM, Zeiss Supra 50VP) was used for micro-structural investigations. Figure 1 illustrates the SEM analysis of sepiolite.

Table 3. Chemical composition of sepiolite sample (wt\%)

\begin{tabular}{cc}
\hline Component & wt.\% \\
\hline $\mathrm{SiO}_{2}$ & 53.47 \\
\hline $\mathrm{MgO}$ & 23.55 \\
\hline $\mathrm{Al}_{2} \mathrm{O}_{3}$ & 0.19 \\
\hline $\mathrm{Fe}_{2} \mathrm{O}_{3}$ & 0.16 \\
\hline $\mathrm{CaO}$ & 0.71 \\
\hline $\mathrm{LO}^{*}$ & 21.49 \\
\hline
\end{tabular}

*LOI: loss of ignition 


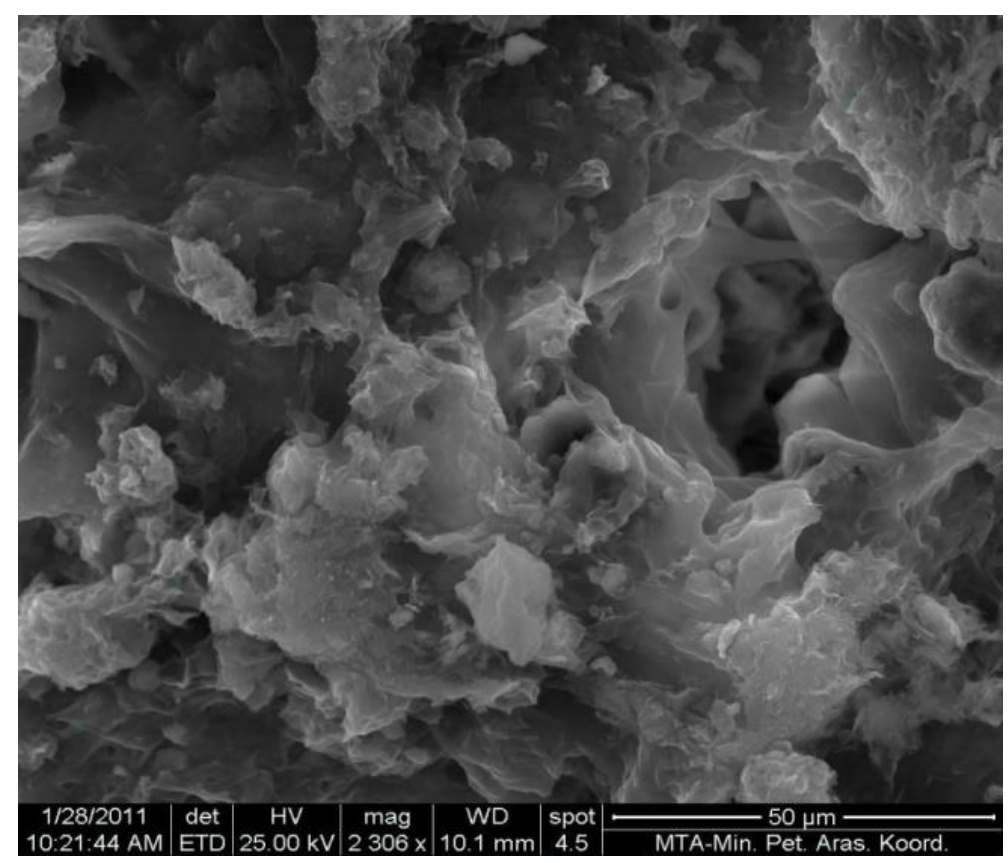

Figure 1. SEM microphotograph of sepiolite crystals with drusy texture

\subsection{Statistical Analysis}

Estimated regression coefficients and related statistics are given in Table 4. In order to determine which of the effects in the model are statistically significant, $p$-values were used. If the $p$-value is less than or equal to 0.05 (commonly used $\alpha$-level), it is concluded that the effect is significant. Since the $p$-values of $X_{2}, X_{3}, X_{4}, X_{2} X_{2}$ and $X_{3} X_{3}$ are less than 0.05 , it was concluded that the effects of these terms are statistically significant.

After identifying a significant set of effects (dosage, concentration, time, squared terms of dosage and concentration), related statistics were then recalculated. Table 5 shows the regression table of the reduced model. This model can be used as the final model to conduct optimization.

Table 4. Estimated regression coefficients

\begin{tabular}{|c|c|c|c|c|}
\hline Term & Coef & SE Coef & $T$ & $\mathrm{P}$ \\
\hline Constant & 60.4138 & 15.0573 & 4.012 & 0.001 \\
\hline $\mathrm{pH}$ & -0.7020 & 2.9962 & -0.234 & 0.818 \\
\hline Dosage & 1.6768 & 0.4770 & 3.515 & 0.003 \\
\hline Concentration & 0.1749 & 0.0793 & 2.206 & 0.042 \\
\hline Time & 0.3674 & 0.1656 & 2.218 & 0.041 \\
\hline $\mathrm{pH}^{*} \mathrm{pH}$ & 0.1018 & 0.2123 & 0.480 & 0.638 \\
\hline Dosage*Dosage & -0.0254 & 0.0067 & -3.808 & 0.002 \\
\hline Concentration*Concentration & -0.0007 & 0.0002 & -3.825 & 0.001 \\
\hline Time*Time & -0.0016 & 0.0008 & -1.972 & 0.066 \\
\hline $\mathrm{pH}^{*}$ Dosage & -0.0211 & 0.0503 & -0.420 & 0.680 \\
\hline $\mathrm{pH}^{*}$ Concentration & 0.0005 & 0.0083 & 0.059 & 0.954 \\
\hline $\mathrm{pH}^{*}$ Time & 0.0022 & 0.0173 & 0.127 & 0.901 \\
\hline Dosage* Concentration & -0.0008 & 0.0015 & -0.522 & 0.609 \\
\hline Dosage*Time & -0.0017 & 0.0031 & -0.564 & 0.581 \\
\hline Concentration*Time & -0.0009 & 0.0005 & -1.696 & 0.109 \\
\hline $\begin{array}{l}S=3.47635 \quad \text { PRESS }=1113.32 \\
R-S q=85.26 \% \quad R-S q(\text { pred })=15.12 \%\end{array}$ & $72.36 \%$ & & & \\
\hline
\end{tabular}

Coef: Coefficient SE Coef: Standard Error of Coefficient T: Student's t test P: Probability 
Table 5. Estimated regression coefficients for reduced model

\begin{tabular}{lcccc}
\hline Term & Coef & SE Coef & T & P \\
\hline Constant & 76.7678 & 4.34511 & 17.668 & 0.000 \\
\hline Dosage & 1.3145 & 0.27254 & 4.823 & 0.000 \\
\hline Concentration & 0.1020 & 0.04723 & 2.159 & 0.041 \\
\hline Time & 0.0395 & 0.02431 & 1.625 & 0.117 \\
\hline Dosage*Dosage & -0.0244 & 0.00650 & -3.759 & 0.001 \\
\hline Concentration*Concentration & -0.0007 & 0.00018 & -3.777 & 0.001 \\
\hline S $=3.42393 \quad$ PRESS $=744.309$ & & & & \\
R-Sq $=77.66 \%$ R-Sq(pred) $=43.25 \%$ R-Sq(adj) $=73.19 \%$ & & & \\
\hline
\end{tabular}

The regression equation in Eq. (2) was created using the values found under the coefficients column in Table 5. According to equation (1), dosage $\left(X_{2}\right)$, and concentration $\left(X_{3}\right)$ have quadratic effects on removal efficiency, while time only has a linear effect. The relationship between dosage and efficiency, and concentration and efficiency follow a curved line, rather than a straight line. Thus, optimum values of these experimental factors can be found.

$y=76.7678+1.3145 \cdot x_{2}+0.1020 \cdot x_{3}+0.0395 \cdot x_{4}-0.0244 \cdot x_{2}^{2}-0.0007 \cdot x_{3}^{2}$

R-square is a goodness-of-fit-measure, and tells how much of the variability in the dependent variable is explained by the independent variables. The adjusted R-square gives a truer estimate by taking into account the number of independent variables. The value of adj. R- square means that $73.19 \%$ of the total variance in the removal efficiency is explained by the experimental factors involved.

The ANOVA results indicate the relative importance of the linear and square sources with respect to the sum of squares (Table 6). The order of factors from high to low contribution on removal efficiency is concentration, dosage, concentration* concentration, dosage*dosage, and time. ANOVA results also show that all the included effects in the model except time are statistically significant at 0.05 level.

Table 6. Analysis of variance for removal efficiency (\%)

\begin{tabular}{lcccccc}
\hline Source & DF & Seq SS & Adj SS & Adj MS & F & P \\
\hline Regression & 5 & 1018.54 & 1018.54 & 203.709 & 17.38 & 0.000 \\
\hline Linear & 3 & 712.44 & 340.39 & 113.464 & 9.68 & 0.000 \\
\hline Dosage & 1 & 247.3 & 272.72 & 272.723 & 23.26 & 0.000 \\
\hline Concentration & 1 & 434.18 & 54.67 & 54.67 & 4.66 & 0.041 \\
\hline Time & 1 & 30.96 & 30.96 & 30.963 & 2.64 & 0.117 \\
\hline Square & 2 & 306.1 & 306.1 & 153.051 & 13.06 & 0.000 \\
\hline Dosage*Dosage & 1 & 138.84 & 165.69 & 165.692 & 14.13 & 0.001 \\
\hline Concentration*Concentration & 1 & 167.26 & 167.26 & 167.26 & 14.27 & 0.001 \\
\hline Residual Error & 25 & 293.08 & 293.08 & 11.723 & & \\
\hline Lack-of-Fit & 9 & 284.92 & 284.92 & 31.658 & 62.08 & 0.000 \\
\hline Pure Error & 16 & 8.16 & 8.16 & 0.51 & & \\
\hline Total & 30 & 1311.62 & & & & \\
\hline
\end{tabular}

Optimization plot gives the best settings for each factor to specified response. Figure 2 recommends sepiolite dosage at $26 \mathrm{~g} \mathrm{I}^{-1}$, initial concentration at $77 \mathrm{mg} \mathrm{l}^{-1}$, and contact time at $42 \mathrm{~min}$. At this setting, the predicted removal efficiency equals to $99.9997 \%$ with a desirability value of 0.99973 . Since there is only a single response variable, this desirability value is basically the same result with composite desirability. 


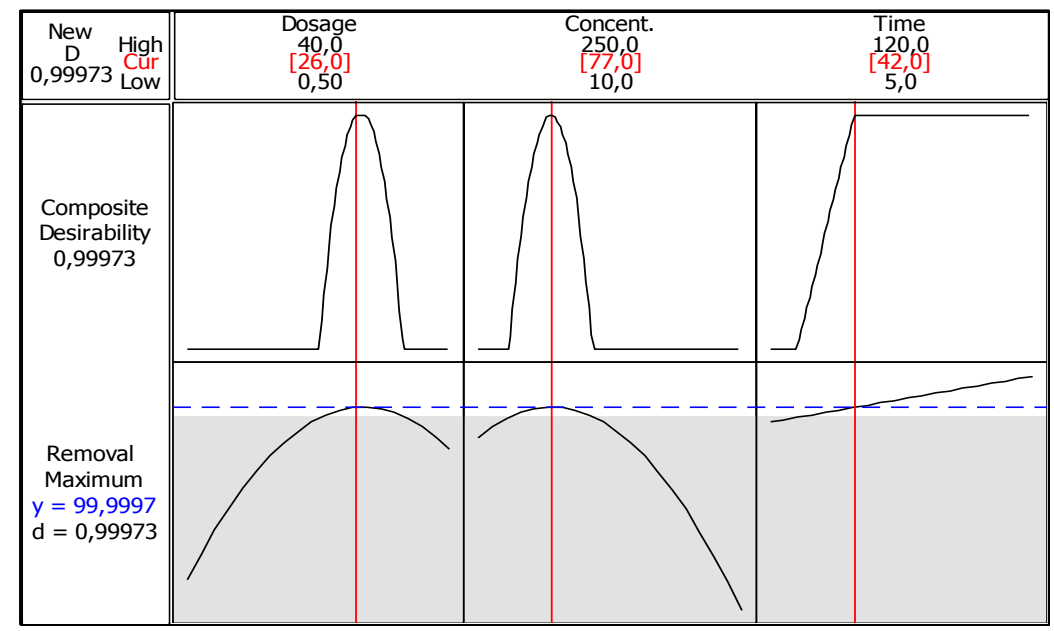

Figure 2. Optimization plot

The contour and surface plots can also be used to visually identify the optimal settings for experimental factors. Since these plots show only two factors at a time, any extra factors are held at a constant level. The contour plot shows multiple combinations of dosage, and concentration that can be used to set the process on target removal efficiency. The surface plot, a three-dimensional wireframe graph, represents the functional relationship between the removal efficiency and the experimental factors, dosage, and concentration.

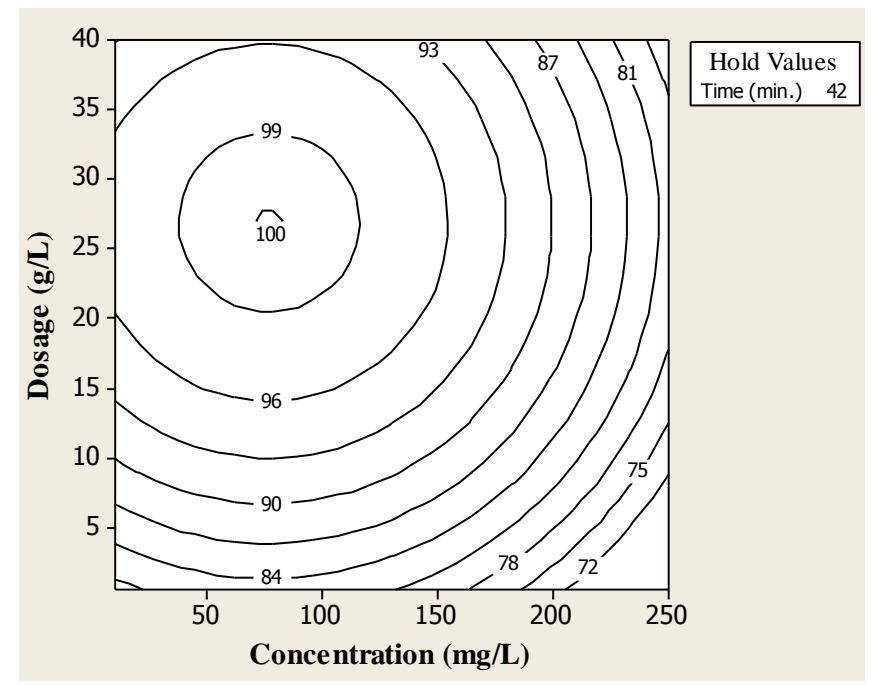

Figure 3. Contour plot of dye removal efficiency

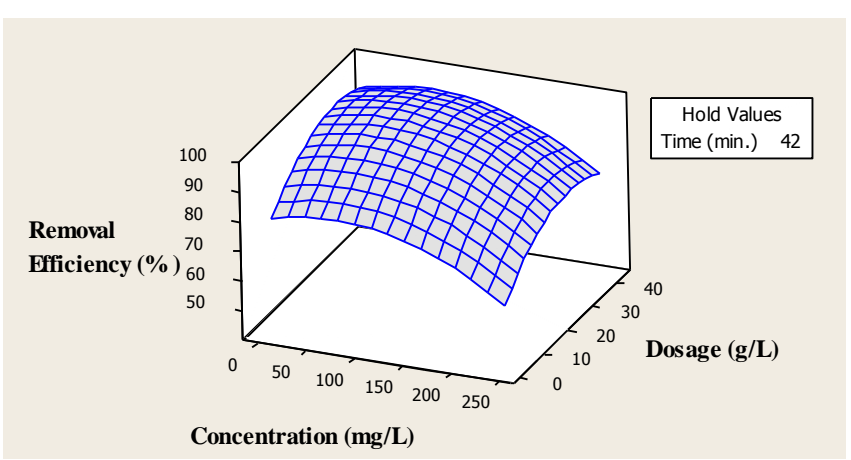

Figure 4. Surface plot of dye removal efficiency 
Initial dye concentrations provide an important driving force to overcome all mass transfer resistance of the dye between the aqueous and sepiolite (Mona et al., 2011). Sepiolite, which is a kind of fibrous silicate clay mineral, is formed of tetrahedral and octahedral sheets. The systematic inversion of tetrahedral and octahedral sheets in the layer is periodically interrupted and the coordination of terminal octahedral ions is completed with strongly bonded water molecules. This mineral structure results in the adsorption sites with high surface irregularities. The adsorption phenomena for such systems are complex (Balci, 2004).

Figure 3 and Figure 4 shows the adsorption of malachite green at different initial dye concentrations with respect to varying sepiolite dosage. At low concentrations, malachite green ions present in the adsorption medium can interact with the binding sites. At high concentrations $\left(250 \mathrm{mg} \mathrm{l}^{-1}\right)$, because of the saturation of the adsorption sites, the rate constant of dye adsorption onto the sepiolite shows a decreasing trend. It may be noted that initial dye concentration was the most significant component of the regression model for the present application, whereas, the initial solution of $\mathrm{pH}$ showed the lowest effect on the dye adsorption efficiency. According to Figure 3 and Figure 4, the maximum efficiency occurs at dosage $26 \mathrm{~g} \mathrm{l}^{-1}$ and concentration $77 \mathrm{mg} \mathrm{l}^{-1}$ when time was kept at $42 \mathrm{~min}$. The predicted maximum efficiency is approximately $99.9 \%$ which is the same as the result from the optimization.

\section{Conclusions}

The present study dealt with malachite green dye removal from aqueous solutions using sepiolite. The performance of sepiolite was modeled and optimized using central composite design. The effects of four important operational parameters including initial $\mathrm{pH}$ of solution, contact time, initial dye concentration, and sepiolite dosage were evaluated by the response surface and counter plots. Analysis of variance (ANOVA) showed the relative significance of process parameters in removal process. The quadratic model was analyzed using ANOVA technique. The $F$ value of the regression was found to be 17.38 with corresponding $p$ value of 0.000 . It implies that the model is significant and can appropriately explain the relation between response and independent variables. Initial concentration, dosage, and contact time were found to be as significant factors. The second-order regression model was developed to predict the removal efficiency using Minitab. The optimal conditions to remove malachite green dye removal from aqueous solution at constant temperature of $23{ }^{\circ} \mathrm{C}$, and stirring speed of $175 \mathrm{rpm}$ were found to be contact time $42 \mathrm{~min}$, initial dye concentration $77 \mathrm{mg} \mathrm{l}^{-1}$, and sepiolite dosage $26 \mathrm{~g} \mathrm{l}^{-1}$. At these conditions, the predicted maximum removal efficiency (99.9\%) was achieved. The present results showed that sepiolite which is received from local resources and low cost materials have a good potential for malachite dye removal from aqueous solution in the industrial application.

\section{References}

Ahmad M.A. and Alrozi R. (2011) Removal of malachite green dye from aqueous solution using rambutan peelbased activated carbon: Equilibrium, kinetic and thermodynamic studies, Chemical Engineering Journal, 171 (2), 510-516.

Alpat S.K., Özbayrak Ö., Alpat Ş. and Akçay H. (2009), The adsorption kinetics and removal of cationic dye, Toludine Blue $\mathrm{O}$, from aqueous solution with Turkish zeolite, Journal of Hazarous Materials, 151, 213-220.

Amani-Ghadima A.R., Abera S., Olad A. and Ashassi-Sorkhabid H. (2013), Optimization of electrocoagulation process for removal of an azo dye usingresponse surface methodology and investigation on the occurrence ofdestructive side reactions, Chemical Engineering and Processing, 64, 68-78.

Ay F., Catalkaya E.C. and Kargi F. (2009), A statistical experiment design approach for advanced oxidation of Direct Red azo-dye by photo-Fenton treatment, Journal of Hazardous Materials, 162, 230-236.

Baek M.H., ljagbemi C.O. and Kim D.S. (2010), Removal of Malachite Green from aqueous solution using degreased coffee bean, Journal of Hazardous Materials, 176, 820-828.

Balci S. (2004), Nature of ammonium ion adsorption by sepiolite: analysis of equilibrium data with several isotherms, Water Research, 38, 1129-1138. 
Bingol D., Tekin N. and Alkan M. (2010), Brilliant Yellow dye adsorption onto sepiolite using full factorial design, Applied Clay Science, 50, 315-321.

DeCarlo N., 2007, Lean Six Sigma, Alpha Books, USA

Garg V.K., Amita M., Kumar R.R. and Gupta R. (2004), Basic dye (methylene blue) removal from simulated wastewater by adsorption using Indian resowood sawdust: a timber industry waste, Dyes Pigments, 63, 243250.

Hameed B.H., Tan A.W. and Ahmad A.L. (2008), Optimization of basic dye removal by oil palm fibre-based activated carbon using response surface methodology, Journal of Hazardous Materials, 158, 324-332.

Im J.K., Cho I.H., Kim S.K. and Zoh K.D. (2012), Optimization of carbamazepine removal in 03/UV/H2O2 system using a response surface methodology with central composite design, Desalination, 285, 306-314.

Lazarevic S., Castvan I.J., Jovanovic D., Milonjic S., Janackovic D. and Petrovic R. (2007), Adsorption of $\mathrm{Pb}^{2+}, \mathrm{Cd}^{2+}$ and $\mathrm{Sr}^{2+}$ ions onto natural and acid-activated sepiolites, Applied Clay Science, 37, 47-57.

Mona S., Kaushik A. and Kaushik C.P. (2011), Waste biomass of Nostoc linckia as adsorbent of crystal violet dye: Optimization based on statistical model, International Biodeterioration \& Biodegradation, 65, 513-521.

Neta J.J.S., Moreira G.C., Silva C.J., Reis C. and Reis E.L. (2011), Use of polyurethane foams for the removal of the Direct Red 80 and Reactive Blue 21 dyes in aqueous medium, Desalination, 281, 55-60.

Nethaji S., Sivasamy A., Thennarasu G. and Saravanan S. (2010), Adsorption of Malachite Green dye onto activated carbon derived from Borassus aethiopum flower biomass, Journal of Hazardous Materials, 181 271-280.

Önal Y., Akmil-Başar C., Eren D., Saricı-Özdemir Ç. and Depci T. (2006), Adsorption kinetics of malachite green onto activated carbon prepared from Tunçbilek lignite, Journal of Hazardous Materials, B128, 150-157.

Özdemir O., Çinar M., Sabah E., Arslan F. and Çelik M.S. (2007), Adsorption of anionic surfactants onto sepiolite, Journal of Hazardous Materials, 147, 625-632.

Rytwo G., Nir S., Margulies L., Casal B., Merino J., Ruiz-Hitzky E. and Serratosa J.M. (1998), Adsorption of monovalent organic cations on sepiolite: experimental results and model calculations, Clays and Caly Minerals, 46 (3), 340-348.

Singh K.P., Gupta S., Singh A.K. and Sinha S. (2011), Optimizing adsorption of crystal violet dye from water by magnetic nanocomposite using response surface modeling approach, Journal of Hazardous Materials, 186, 1462-1473.

Somayajula A., Asaithambi P., Susree M., and Matheswaran M. (2012), Sonoelectrochemical oxidation for decolorization of Reactive Red 195, Ultrasonics Sonochemistry, 19, 803-811.

Şener S. (2008), Use of solid wastes of the soda ash plant as an adsorbent for the removal of anionic dyes: Equilibrum and kinitic studies, Chemical Engineering Journal, 138, 1-3, 207-214.

Tor A. and Cengeloglu Y. (2006), Removal of congo red from aqueous solution by adsorption onto acid active red mud, Journal of Hazardous Materials, B 138, 409-415.

Turan M., Mart U., Yüksel B. and Çelik M.S. (2005), Lead removal in fixed-bed columns by zeolite and sepiolite. Chemosphere, 60, 1487-1492.

Uğurlu M. (2009), Adsorption of a textile dye onto activated sepiolite, Microporous and Mesoporous Materials, 119, $276-283$.

Zhao M., Tang Z. and Liu P. (2008), Removal of methylene blue from aqueous solution with silica nano-sheets derived from vermiculite, Journal of Hazarous Materials, 158, 43-51. 